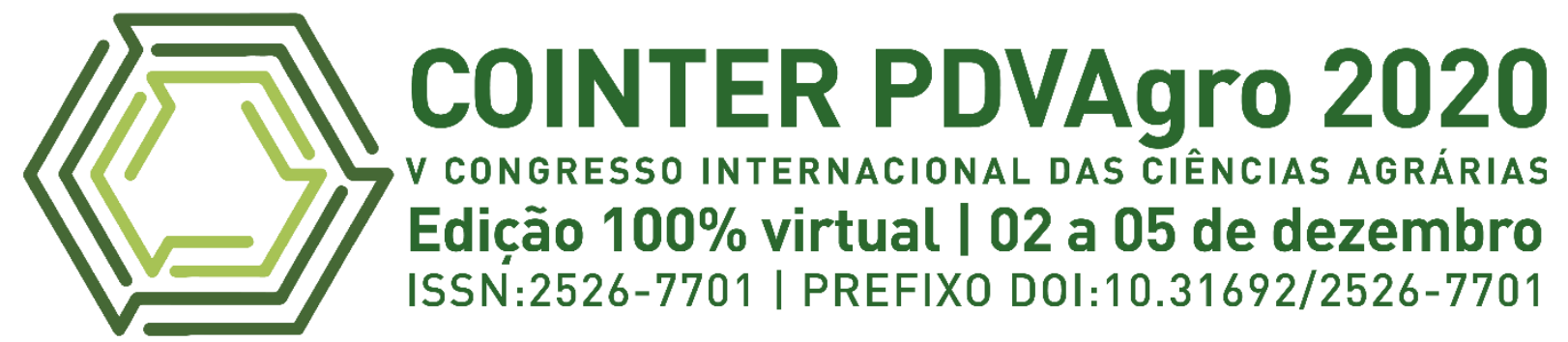

\title{
EFEITO DA ADIÇÃO DO SORO DE LEITE NA ELABORAÇÃO DE PRODUTOS CÁRNEOS
}

\section{EFECTO DE LA ADICIÓN DE SERUM DE LECHE EN LA PREPARACIÓN DE PRODUCTOS CÁRNICOS}

\section{EFFECT OF THE ADDITION OF WHEY ON THE PREPARATION OF MEAT PRODUCTS}

\author{
Apresentação: Comunicação Oral
}

Ana Thaís Campos de Oliveira ${ }^{1}$; Antonia Lucivânia de Sousa Monte ${ }^{2}$; Fernanda Tayla de Sousa Silva ${ }^{3}$; Everlândia Silva Moura Miranda ${ }^{4}$; Andreia Rodrigues da Silva ${ }^{5}$

\begin{abstract}
RESUMO
A procura por alimentos mais saudáveis tem aumentado nos últimos anos e essa tendência tem influenciado também na produção de embutidos. Os produtos cárneos geralmente possuem um teor de gordura mais elevado que a carne fresca, podendo conter entre $30 \%$ a $40 \%$ em uma linguiça, além de diversos tipos de aditivos químicos adicionados. Assim o emprego de ingredientes naturais pode enriquecer nutricionalmente o alimento, bem como promover melhorias nos seus aspectos tecnológicos, o que poderia ser uma excelente saída para a produção desses produtos. Diversos estudos estão empregando o soro de leite na produção de embutidos. O soro de leite é um subproduto da indústria de laticínios e possui propriedades nutritivas, contendo proteínas solúveis, lactose, minerais e vitaminas, podendo assim ser utilizado como um aditivo natural em produtos cárneos. Dessa forma, este trabalho teve como objetivo analisar a influência exercida pelo soro de leite sobre os embutidos, buscando compreender os benefícios promovidos pela sua aplicação. Isso foi possível através da realização de uma revisão sistemática, onde foram analisados dados obtidos de diversos estudos. Foi possível perceber a influência positiva exercida pelo soro de leite sobre os embutidos, agindo diretamente sobre as suas propriedades físico-químicas e sensoriais. As publicações mostraram as várias formas de utilização do soro de leite, que pode ser aplicado como concentrado proteico, soro ácido, soro fluido e soro em pó, podendo ser utilizado como um aditivo alimentar, substituindo conservantes, antioxidantes, e também substituto de gordura. Entende-se assim que a aplicação do soro em embutidos é uma estratégia positiva para tornar o alimento mais saudável.
\end{abstract}

DOI : $\underline{\text { https://doi.org/10.31692/2526-7701.VCOINTERPDVAgro.0495 }}$

Palavras-Chave: embutidos, subproduto, alimentos saudáveis.

\section{RESUMEN}

La demanda de alimentos más saludables ha aumentado en los últimos años y esta tendencia también ha

\footnotetext{
${ }^{1}$ Mestranda em Tecnologia de Alimentos, Instituto Federal de Educação, Ciência e Tecnologia do Ceará (IFCE), euthaiscampos.alimentos@gmail.com

${ }^{2}$ Docente, Instituto Federal de Educação, Ciência e Tecnologia do Ceará (IFCE), lucivania@ifce.edu.br

${ }^{3}$ Mestranda em Tecnologia de Alimentos, Instituto Federal de Educação, Ciência e Tecnologia do Ceará (IFCE), tayliinhaf@gmail.com

${ }^{4}$ Mestranda em Tecnologia de Alimentos, Instituto Federal de Educação, Ciência e Tecnologia do Ceará (IFCE), everlandiamoura7@yahoo.com

${ }^{5}$ Docente, Instituto Federal de Educação, Ciência e Tecnologia do Ceará (IFCE), andreia.rodrigues@ifce.edu.br
} 


\section{EFEITO DA ADIÇÃO DO SORO DE LEITE}

influido en la producción de embutidos. Los productos cárnicos generalmente tienen un mayor contenido de grasa que la carne fresca y pueden contener entre $30 \%$ y $40 \%$ en una salchicha, además de varios tipos de aditivos químicos agregados. Así, el uso de ingredientes naturales puede enriquecer nutricionalmente el alimento, además de promover mejoras en sus aspectos tecnológicos, lo que podría ser una excelente salida para la elaboración de estos productos. Varios estudios están utilizando suero de leche en la producción de embutidos. El suero es un subproducto de la industria láctea y tiene propiedades nutricionales, contiene proteínas solubles, lactosa, minerales y vitaminas, por lo que se puede utilizar como aditivo natural en productos cárnicos. Así, este trabajo tuvo como objetivo analizar la influencia que ejerce el suero de leche en los embutidos, buscando comprender los beneficios que promueve su aplicación. Esto fue posible a través de una revisión sistemática, donde se analizaron los datos obtenidos de varios estudios. Se pudo percibir la influencia positiva que ejerce el suero sobre el embutido, actuando directamente sobre sus propiedades físico-químicas y sensoriales. Las publicaciones mostraron las diversas formas de uso del suero, que se puede aplicar como concentrado proteico, suero ácido, suero líquido y suero en polvo, y se puede usar como aditivo alimentario, reemplazando conservantes, antioxidantes y también como sustituto de grasas. Se entiende que la aplicación de suero en embutidos es una estrategia positiva para hacer los alimentos más saludables.

Palabras Clave: embutidos, subproducto, alimentos saludables.

\section{ABSTRACT}

The demand for healthier foods has increased in recent years and this trend has also influenced the production of sausages. Meat products generally have a higher fat content than fresh meat, and may contain between $30 \%$ to $40 \%$ in a sausage, in addition to several types of chemical additives added. Thus, the use of natural ingredients can nutritionally enrich the food, as well as promoting improvements in its technological aspects, which could be an excellent outlet for the production of these products. Several studies are using whey in the production of sausages. Whey is a by-product of the dairy industry and has nutritional properties, containing soluble proteins, lactose, minerals and vitamins, and can thus be used as a natural additive in meat products. Thus, this work aimed to analyze the influence exerted by whey on sausages, seeking to understand the benefits promoted by their application. This was possible through a systematic review, where data obtained from several studies were analyzed. It was possible to perceive the positive influence exerted by whey on sausages, acting directly on its physicalchemical and sensory properties. The publications showed the various ways of using whey, which can be applied as a protein concentrate, acid whey, fluid whey and powdered whey, and can be used as a food additive, replacing preservatives, antioxidants, and also a fat substitute. It is understood that the application of whey in sausages is a positive strategy to make food healthier.

Keywords: sausages, by-product, healthy food.

\section{INTRODUÇÃO}

Nos últimos anos o mercado consumidor tem se tornado cada vez mais exigente dando preferência aos alimentos mais nutritivos, com redução de gordura e de agentes químicos empregados em seu processo. Essa tendência tem sido vista também na produção de embutidos, que vem desenvolvendo técnicas para o melhoramento dos seus produtos, com uma visão de buscar alimentos mais saudáveis e seguros para o consumo.

Tendo o seu surgimento na antiguidade, os embutidos foram desenvolvidos no intuito de ampliar o tempo de vida útil de carnes que se deterioravam rapidamente. Dessa forma percebeu-se que após picar, salgar, adicionar aromatizantes, embutir e se dessecar, a carne adquiria propriedades sensoriais agradáveis, além de estender o seu prazo de validade (ORDONEZ et al., 2005). 
Os produtos cárneos geralmente possuem um teor de gordura mais elevado que a carne fresca, podendo conter entre 30\% a 40\% em uma linguiça. Assim o emprego de ingredientes naturais pode enriquecer nutricionalmente o alimento, bem como promover melhorias nos seus aspectos tecnológicos. Diversos estudos estão empregando o soro de leite na produção de embutidos (MARTINS et al., 2009).

O soro de leite é um subproduto da indústria de laticínios, representando a porção aquosa liberada do coágulo durante a fabricação convencional de queijos. Ele possui propriedades nutritivas, contendo proteínas solúveis lactose, minerais e vitaminas, ácido lático e nitrogênio não solúvel. Apesar de todos esses benefícios, ele é um agente altamente poluidor quando mal manejado, destinado diretamente a rios ou esgoto público. Assim seu aproveitamento na produção de alimentos contribuirá para o meio ambiente (ALVES et al., 2014).

Dessa foram necessita-se haver um aprofundamento em pesquisas para assim entender quais as contribuições que o soro de leite pode incorporar aos embutidos. Este trabalho tem como objetivo analisar a influência exercida pelo soro de leite sobre os embutidos, buscando compreender quais os benefícios promovidos pela sua aplicação. Isso tudo através de uma revisão sistemática utilizando bases de pesquisas, analisando dados obtidos a partir das publicações. A partir disso os objetivos centrais foram:

1. Avaliar quais estudos utilizavam o soro de leite para aplicação em embutidos;

2. Identificar quais foram as formas empregadas para de utilização do soro de leite nos embutidos;

3. Avaliar a eficiência dessas metodologias a partir das modificações das propriedades sensoriais e físico-químicas de cada produto.

\section{FUNDAMENTAÇÃO TEÓRICA}

\section{Embutidos}

Os Produtos cárneos são alimentos elaborados totalmente ou parcialmente com carne, obtida de animais de abate, com adição ou não de ingredientes de origem animal ou vegetal, especiarias e aditivos. O processo de embutir ocorre a partir da introdução da massa de carne preparada na tripa, previamente selecionada (ORDONEZ et al., 2005).

Há uma grande variedade desses produtos, dentre eles os frescos, como o hambúrguer. Também os embutidos cruz curados, que são produzidos a partir de carne e gorduras picadas com ou sem miúdos, sendo incorporadas especiarias, aditivos e condimentos, passando por processo de maturação e defumação que é opcional. Nesse grupo encontram-se salsichão, salame, linguiça e etc (ORDONEZ et al., 2005). 


\section{EFEITO DA ADIÇÃO DO SORO DE LEITE}

Segundo o Regulamento da Inspeção Industrial e Sanitária de Produtos de Origem Animal (2017), os embutidos são produtos cárneos elaborados com carne ou com órgãos comestíveis, curados ou não, condimentados, cozidos ou não, defumados e dessecados ou não, tendo como envoltório a tripa, a bexiga ou outra membrana animal. Dentre os produtos, são considerados embutidos, linguiça, morcela, mortadela, salsicha, salame e pepperoni.

Hoje os embutidos são amplamente aceitos em todo o mundo, mas com o passar dos anos, o mercado consumidor vem procurando alimentos mais saudáveis, assim a reformulação desses produtos cárneos pode ser uma saída. A gordura é essencial para todas as características do embutido, como textura e sabor, mas a incorporação de ingredientes naturais pode beneficiar nutricionalmente este produto (ŠOJIĆ et al.,2018).

\section{Soro de leite}

O soro de leite é um subproduto da indústria de laticínios, representando a porção aquosa liberada do coágulo durante a fabricação convencional de queijos. Representa cerca de 85 a 90 $\%$ do volume de todo o leite que é utilizado na produção de queijos, podendo reter aproximadamente $55 \%$ dos nutrientes dos queijos, possuindo assim propriedades nutritivas, contento em sua composição proteínas solúveis lactose, minerais e vitaminas, ácido lático e nitrogênio não solúvel. Ele é um líquido opaco com cor amarelo-esverdeado de aspecto turvo e sabor fresco, ligeiramente doce ou ácido (ALVES et al., 2014).

Segundo Pacheco et al (2017), a composição do soro de leite pode vai variar de acordo com composição química do leite, a alimentação e reprodução do animal e do clima. Além disso, tipo coagulação e da operação de produção do queijo vai influenciar diretamente no sabor. A obtenção do soro acontece por coagulação enzimática do leite, através da adição de renina, ou por coagulação ácida (OLIVEIRA et al., 2013). Mas apesar de todos os benefícios ele pode trazer a um alimento, ele também é um agente altamente poluidor quando manejado inadequadamente e lançado sem tratamento para rios e esgotos públicos. Assim seu aproveitamento na produção de alimentos é um aliado também para o meio ambiente (TERRA et al., 2009).

Alguns estudos são realizados para utilização do soro como fonte em produtos cárneos, Martins et al. (2009) e Cruz (2014) empregaram o soro de leite fluido na elaboração de mortadelas, e através de seus resultados foi possível observar que os produtos mantiveram o padrão de qualidade ao ser comparado com o comercial, apresentando boa aceitabilidade sensorial, além de elevar o percentual de proteico do embutido. 


\section{METODOLOGIA}

A revisão sistemática é uma metodologia de pesquisa onde se utiliza de dados da literatura, investigando sobre determinada temática, a partir de sistemas de buscas, avaliando, interpretando e selecionando de maneira crítica e imparcial as informações ali encontradas (SAMPAIO ; MANCINI, 2007). A Revisão sistemática se caracteriza por sintetizar informações disponíveis, em certo tempo, sobre um algo específico, para que de forma objetiva, esses dados possam ser reproduzidos por intermédio de método científico. Este tipo de revisão se difere da tradicional, pois procura possíveis vieses em todas as etapas, por meio de rigoroso método de busca e seleção das pesquisas, através da avaliação da coleta, síntese e interpretação dos dados encontrados, promovendo a avaliação da sua relevância e validação (GALVÃO SAWADA; TREVIZAN, 2004).

Dessa forma para e iniciar uma revisão sistemática, três pontos precisam ser considerados, o objetivo da pesquisa, identificar a literatura e selecionar os trabalhos que possivelmente serão incluídos (SAMPAIO ; MANCINI, 2007). Assim sendo, este estudo está divididos em três etapas, que estão expostas na figura 01 .

Figura 01- Processo utilizado para elaboração da revisão sistemática.

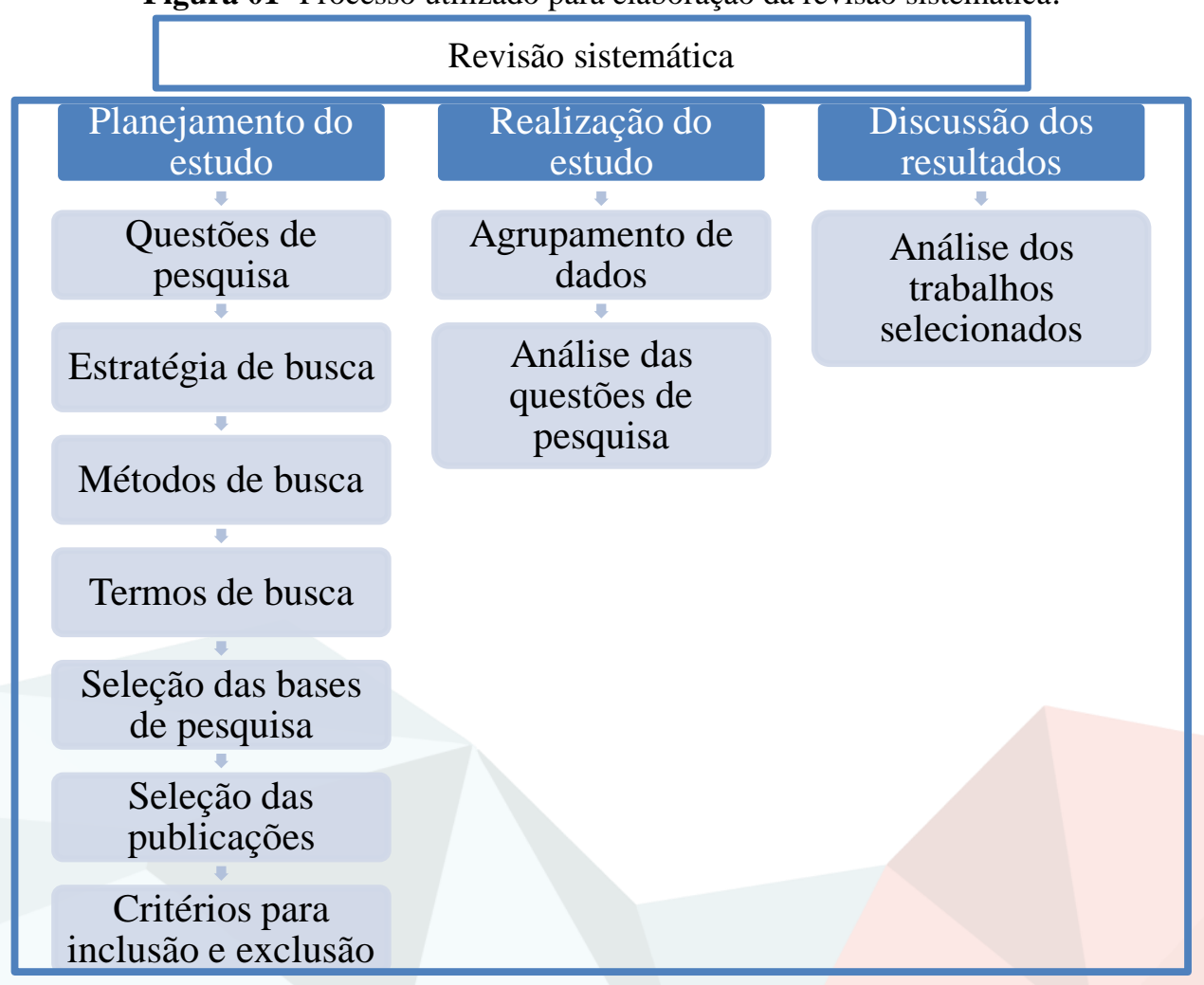

\section{Planejamento do estudo}

Fonte: Própria (2019).

- Questões de pesquisas

Para nortear o estudo e desse modo adquirir as informações almejadas, foram nomeadas 


\section{EFEITO DA ADIÇÃO DO SORO DE LEITE}

algumas questões que se relacionavam diretamente com os objetivos. A partir disso cinco questões principais foram levantadas com fins específicos, para que dessa forma o estudo pudesse ser melhor desenvolvido e assim obter resultados positivos e uma maior contribuição realizada por esta revisão.

- Q1: Qual embutido foi utilizado no estudo? A finalidade dessa pergunta é entender quais tipos de embutidos já tinham sido estudados com aplicação do soro do leite em sua composição.

- Q2: Como o soro foi aplicado? O soro de leite pode ser aplicado de diversas formas, então essa pergunta objetiva entender quais os estudos e as formas de aplicação do soro de leite em embutidos.

- Q3: Os resultados da aplicação do soro foram positivos? O propósito dessa pergunta é compreender se a aplicação do soro de leite trouxe alguma modificação positiva para o embutido.

- Q4: Quais contribuições nutritivas o soro trouxe para essa pesquisa? O objetivo dessa questão é identificar quais as contribuições nutritivas que a aplicação do soro de leite trouxe para o embutido, já que são produtos alimentícios que normalmente contém grande quantidade de gordura e também aditivos químicos. Dessa forma esta pergunta busca compreender se houve algum benefício nutricional a partir da aplicação do soro de leite.

- Q5: Quais interferências houveram para as propriedades sensoriais? Esta pergunta procura entender se a partir da aplicação do soro do leite houveram ou não modificações em relação as propriedades sensoriais, sejam sabor, textura, cor.

- Estratégia de busca

Após definidas as questões de pesquisas, para garantir a viabilidade do estudo, a estratégia de busca é fundamental, para assegurar que os trabalhos incluídos sejam relevantes para a pesquisa. Assim sendo, a partir do tema deste estudo foram realizadas algumas combinações de termos e efetuou-se a pesquisa.

- Métodos de buscas

Para a realização da pesquisa foram utilizados os termos de buscas, junto a operadores lógicos em bases de pesquisas eletrônicas, para que assim pudesse ser obtido um grande número de trabalhos, sendo uma busca mais efetiva, ao invés ser feita manualmente, podendo deixar de fora estudos relevantes. Dessa forma, foi estabelecida a seguinte sequência:

- Especificou-se os termos correspondentes a pesquisa; 
- Traduziu-se os termos para o idioma inglês;

- Utilizar o operador lógico “OR” para associar os sinônimos;

- Utilizar o operador lógico “AND” para unir termos.

- Termos de buscas

Baseado no tema e nas questões de pesquisa, foram escolhidos os termos de buscas para aplicação nas bases de dados eletrônicas. Dessa forma sinônimos foram utilizados com auxílio dos operadores lógicos, para que a expressão pudesse ser formada, e obter bons resultados ao ser executadas nessas bases. Dessa forma os termos escolhidos para a pesquisa foram: (“sausage" OR “sausages”) AND “whey”.

- Seleção das bases de pesquisa

Para a realização do estudo algumas bases de dados foram consultadas, sendo elas: Scientific Eletronic Library Online (SciELO), ScienceDirect, PubMed e Periódicos da Capes. A partir daí os descritores foram utilizados, havendo-se então a seleção dos artigos.

- Seleção das publicações

Após a definição dos termos e bases, a pesquisa foi executada com o retorno de muitos trabalhos. Em seguido aplicou-se um primeiro filtro, onde os títulos e resumos são lidos para identificar se corresponde ou não a temática que está sendo pesquisada, havendo assim a inclusão ou exclusão do artigo. Essas publicações selecionadas foram lidas em completo, para que assim através da análise do texto pudesse haver aplicação de um segundo filtro e a inclusão ou não desses artigos, conforme figura 02. Para essas publicações escolhidas realizou-se a análise completa e aplicada as questões pesquisa que haviam sido estipuladas. Outros parâmetros de inclusão e exclusão também foram aplicados, o tipo de publicação, que deveria ser artigo científico, também o período, sendo selecionados apenas artigos publicados entre 2009 e 2019, e o outro foi o idioma, sendo selecionados os artigos em português, inglês e espanhol.

Figura 02 - Processo de seleção das publicações.

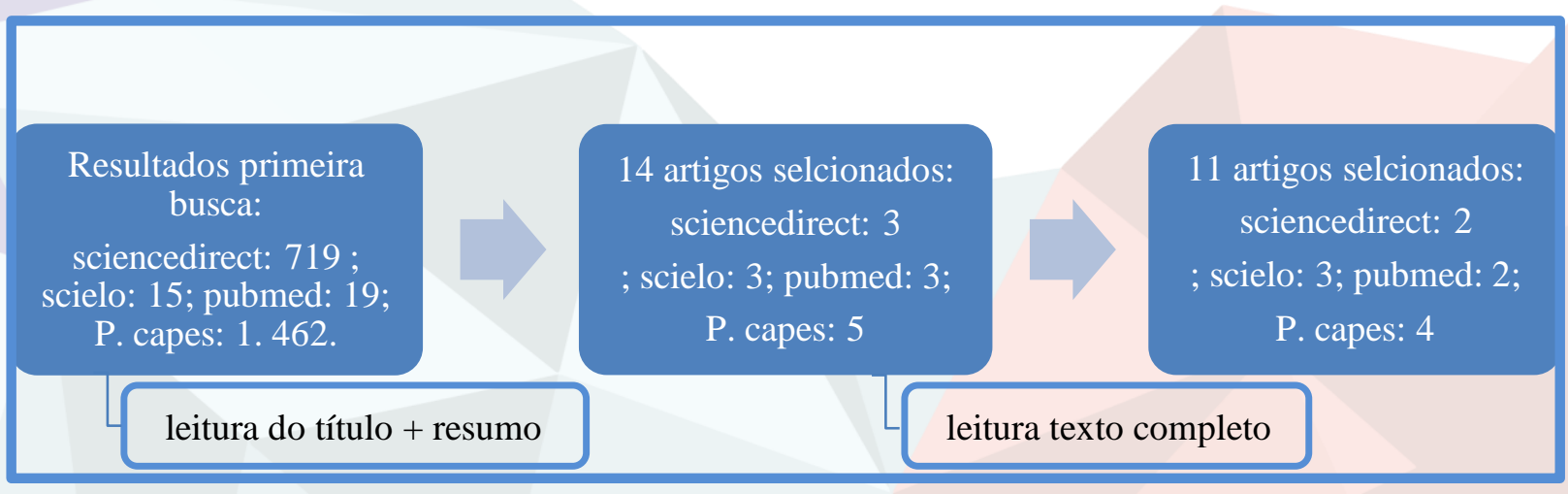

Fonte: Própria (2019). 


\section{RESULTADOS E DISCUSSÃO}

\section{Realização do estudo}

Inicialmente será mostrado uma visão geral dos resultados alcançados com a pesquisa, seguido das análises das questões das respostas obtidas.

- Dados coletados

Como pode ser visto na figura 02, a busca inicial teve um retorno de 2.215 artigos, mesmo sendo aplicados critérios como tipo de publicação que era somente artigos, período que iria de 2009 a 2019 (português, inglês e espanhol). A partir daí, com a utilização do primeiro filtro (leitura título e resumo), foram selecionados 14 artigos. Os que passavam por esse primeiro filtro eram lidos por completo o texto, passando assim pelo segundo filtro, no qual foram selecionados 11 artigos. A tabela 01 mostra os artigos que foram selecionados com seus autores, ano de publicação, títulos traduzidos e origem.

Tabela 01- Identificação dos artigos selecionados

\begin{tabular}{|c|c|c|c|}
\hline ID & Referências & $\begin{array}{c}\text { Títulos } \\
\end{array}$ & Origem \\
\hline A1 & $\begin{array}{c}\text { FERREIRA; } \\
\text { FONSECA; } \\
\text { SANTOS, 2009 }\end{array}$ & $\begin{array}{l}\text { Composição centesimal e } \\
\text { aceitação de linguiça } \\
\text { elaborada com teor reduzido } \\
\text { de gordura e adicionada de } \\
\text { concentrados proteicos de } \\
\text { soro de leite } \\
\end{array}$ & Scielo \\
\hline A 2 & $\begin{array}{l}\text { WÓJCIAK; } \\
\text { DOLATOWSKI, } \\
2016\end{array}$ & $\begin{array}{c}\text { Avaliação de conservantes } \\
\text { naturais em combinaçãa com } \\
\text { soro ácido para uso em } \\
\text { salame }\end{array}$ & Scielo \\
\hline A3 & $\begin{array}{c}\text { WÓJCIAK; } \\
\text { KARWOWSKA; } \\
\text { DOLATOWSKI, } \\
2015\end{array}$ & $\begin{array}{c}\text { Uso de soro ácido e mostarda } \\
\text { para substituir os nitritos } \\
\text { durante a produção de } \\
\text { salames }\end{array}$ & Scielo \\
\hline A4 & $\begin{array}{c}\text { WÓJCIAK; } \\
\text { KARWOWSKA; } \\
\text { DOLATOWSKI, } \\
2014\end{array}$ & $\begin{array}{l}\text { Efeito do soro ácido na } \\
\text { concentração de } \\
\text { nitrosilmioglobina em } \\
\text { salames }\end{array}$ & ScienceDirect \\
\hline A5 & $\begin{array}{l}\text { WÓJCIAK; } \\
\text { DOLATOWSKI, } \\
2015\end{array}$ & $\begin{array}{l}\text { Efeito do soro ácido na } \\
\text { concentração de } \\
\text { nitrosilmioglobia e salsicha } \\
\text { fermentada. }\end{array}$ & ScienceDirect \\
\hline A6 & $\begin{array}{l}\text { KARWOWSKA; } \\
\text { DOLATOWSKI, } \\
2017\end{array}$ & $\begin{array}{c}\text { Efeito do soro ácido e } \\
\text { cranberries liofilizados na } \\
\text { oxidação lipídica e na } \\
\text { composição de ácidos graxos } \\
\text { de salames isenta de nitrito / } \\
\text { nitrato feita a partir de carne } \\
\text { de cervo }\end{array}$ & Pubmed \\
\hline
\end{tabular}




\begin{tabular}{|c|c|c|c|}
\hline EA7 & $\begin{array}{l}\text { KARWOWSKA; } \\
\text { WÓJCIAK; } \\
\text { DOLATOWSKI, } \\
2015\end{array}$ & $\begin{array}{l}\text { Influência do soro ácido e da } \\
\text { semente de mostarda na } \\
\text { oxidação lipídica de salames } \\
\text { orgânicas sem nitrito }\end{array}$ & Pubmed \\
\hline EA8 & $\begin{array}{c}\text { WÓJCIAK; } \\
\text { DOLATOWSKI; } \\
\text { KOŁOŻYN- } \\
\text { KRAJEWSKA,2015 }\end{array}$ & $\begin{array}{l}\text { Uso de whey ácido e cepas } \\
\text { probióticas para melhorar a } \\
\text { qualidade microbiológica e a } \\
\text { aceitação sensorial da } \\
\text { salames }\end{array}$ & Capes \\
\hline A9 & ZOUARI et al., 2012 & $\begin{array}{l}\text { Whey powder, } 1 \text {-carragenina, } \\
\text { e interações de gordura e sua } \\
\text { influência na textura } \\
\text { instrumental e nas } \\
\text { propriedades sensoriais da } \\
\text { salsicha de carne de peru } \\
\text { usando uma abordagem de } \\
\text { design de mistura }\end{array}$ & Capes \\
\hline A10 & $\begin{array}{l}\text { KARWOWSKA; } \\
\text { KONONIUK, } 2018\end{array}$ & $\begin{array}{l}\text { A adição de soro ácido } \\
\text { melhorando salmes } \\
\text { fermentada a seco sem a } \\
\text { produção de nitrito e seu } \\
\text { valor nutricional }\end{array}$ & Capes \\
\hline A11 & $\begin{array}{l}\text { MARTINS et al., } \\
2009\end{array}$ & $\begin{array}{l}\text { Emprego de soro de leite } \\
\text { liquido na elaboracao de } \\
\text { mortadela }\end{array}$ & Capes \\
\hline
\end{tabular}

Os artigos científicos foram organizados e analisados segundo seus objetivos, metodologia, solução propostas e conclusão de acordo com o que está descrito no quadro 01 . 


\begin{tabular}{|c|c|c|}
\hline 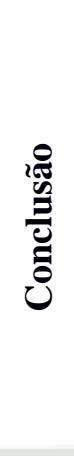 & 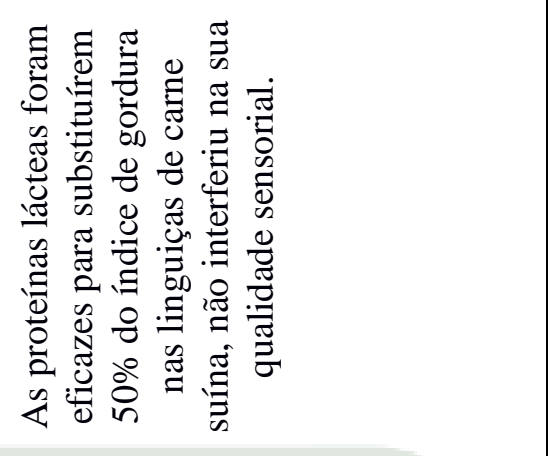 & 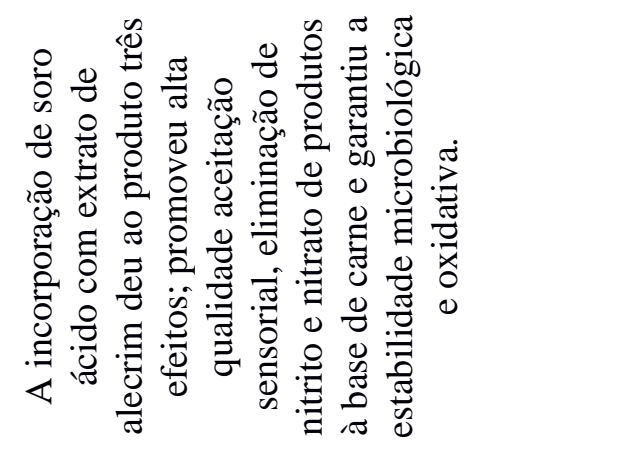 \\
\hline 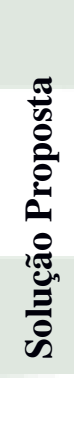 & 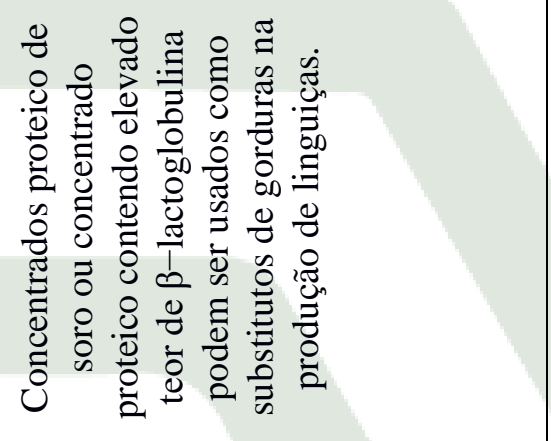 & 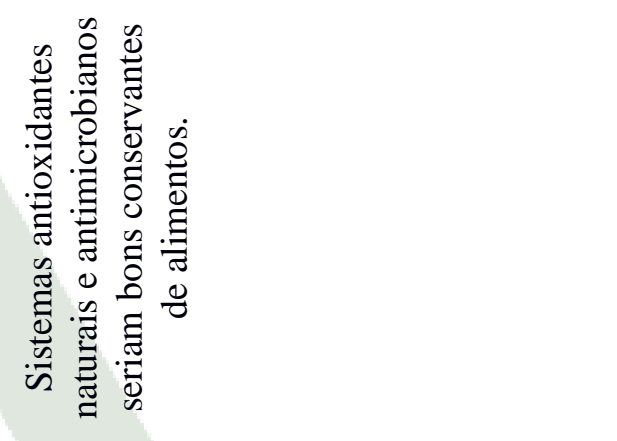 \\
\hline $\begin{array}{l}\frac{\pi}{00} \\
\frac{0}{0} \\
\frac{0}{0} \\
\frac{0}{0} \\
\frac{0}{2}\end{array}$ & 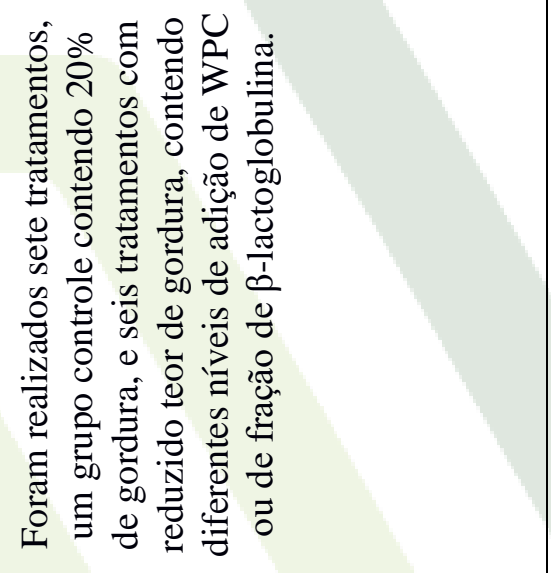 & 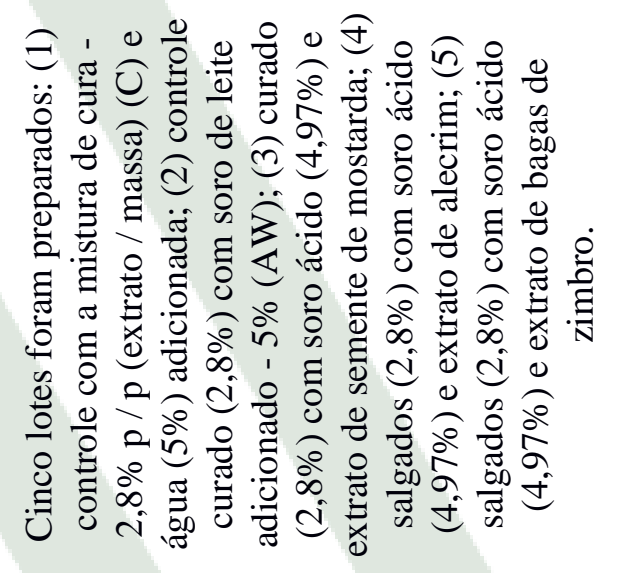 \\
\hline$\frac{e_{0}^{0}}{\frac{0}{0}}$ & 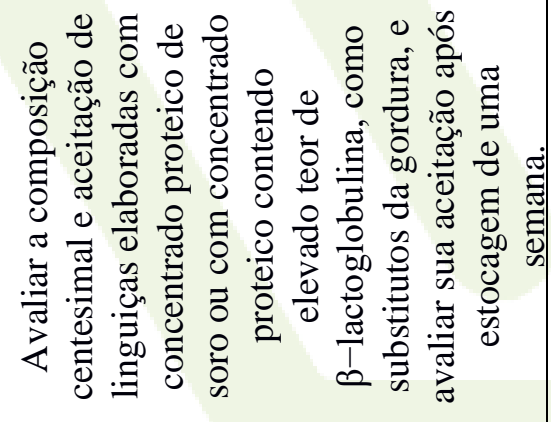 & 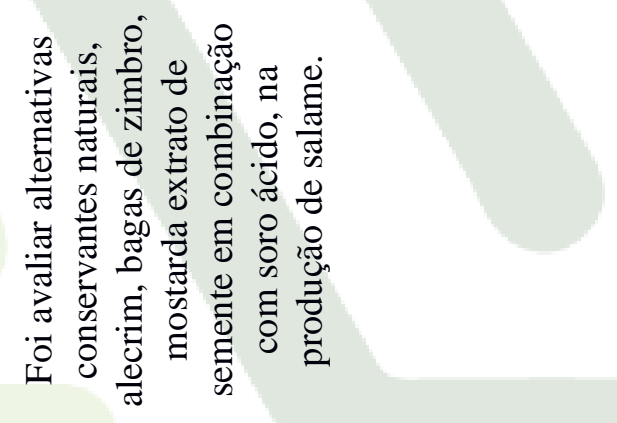 \\
\hline 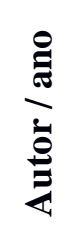 & 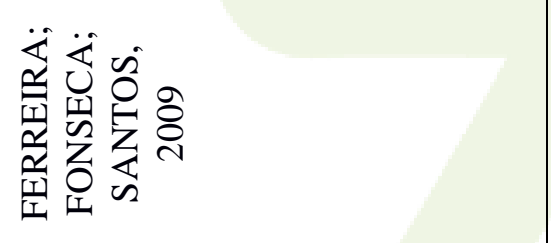 & 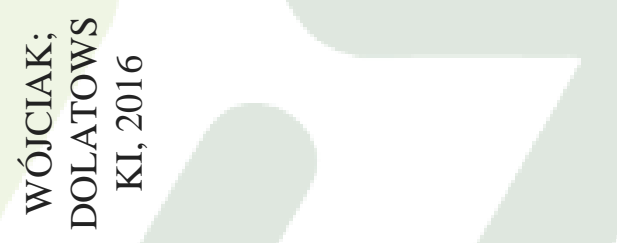 \\
\hline
\end{tabular}




\begin{tabular}{|c|c|c|}
\hline 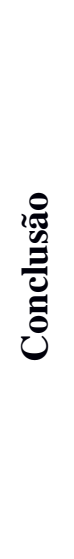 & 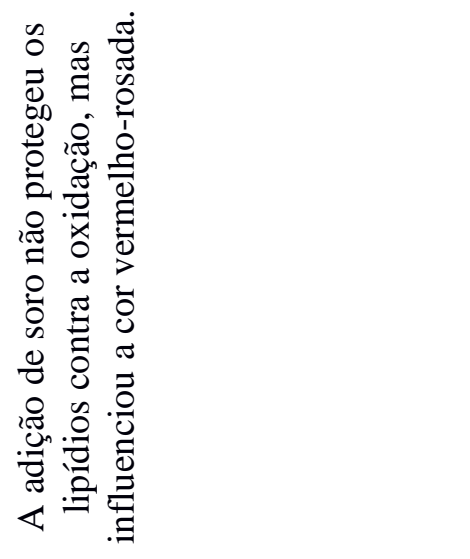 & 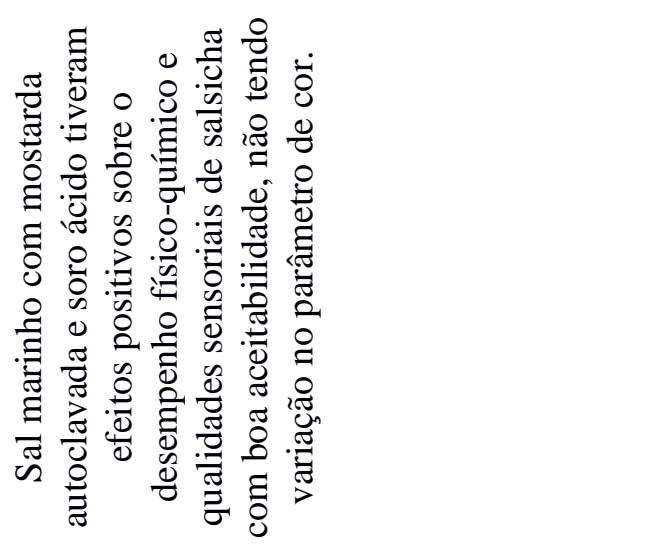 \\
\hline 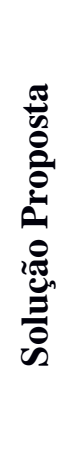 & 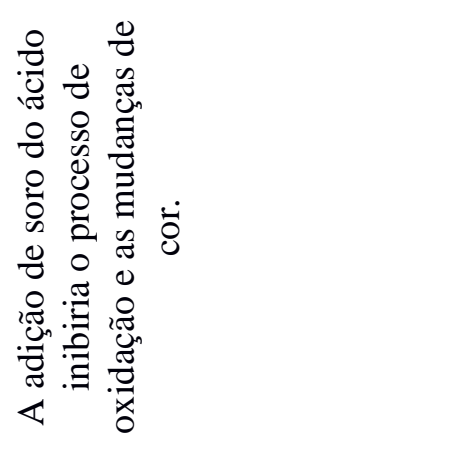 & 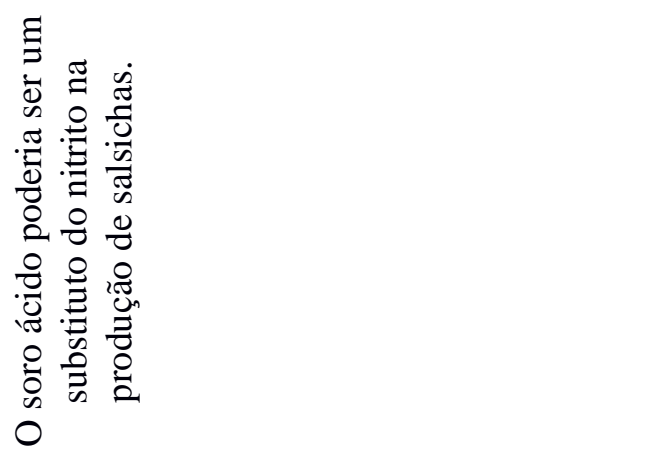 \\
\hline 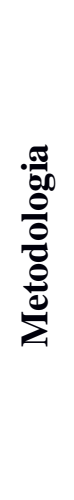 & 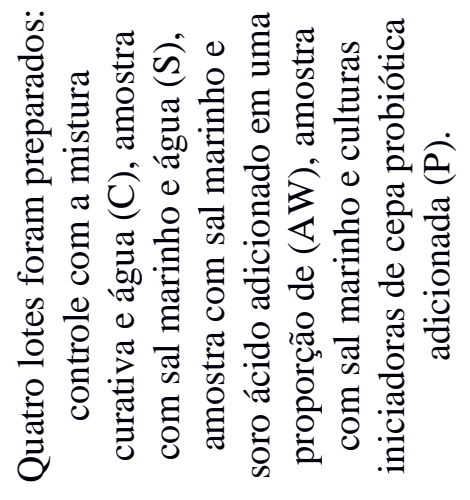 & 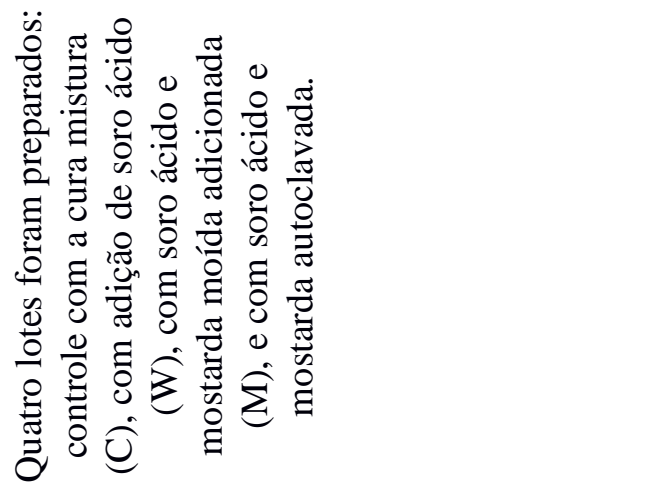 \\
\hline$\frac{\sum_{0}^{0}}{0}$ & 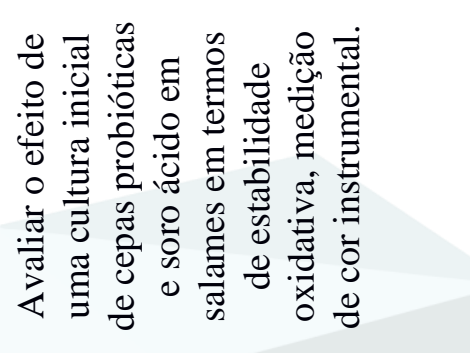 & 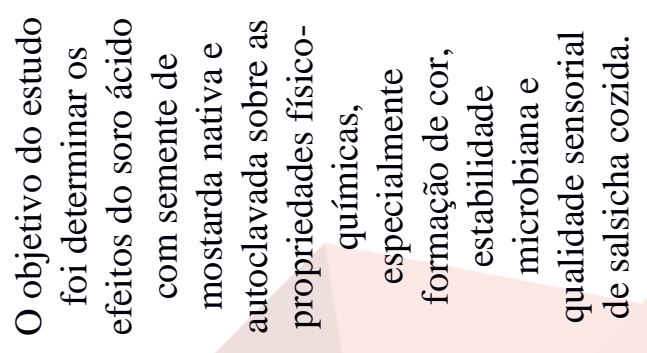 \\
\hline 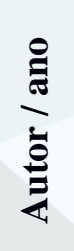 & 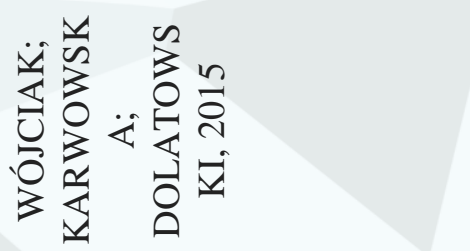 & 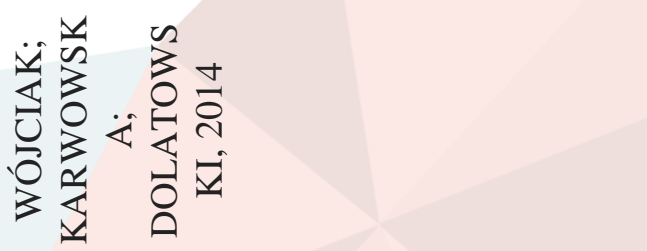 \\
\hline
\end{tabular}




\begin{tabular}{|c|c|c|c|}
\hline ن̊ & 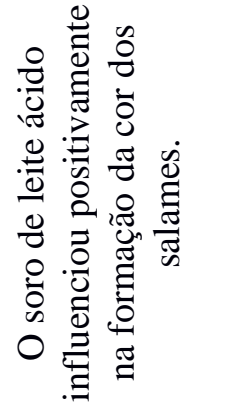 & 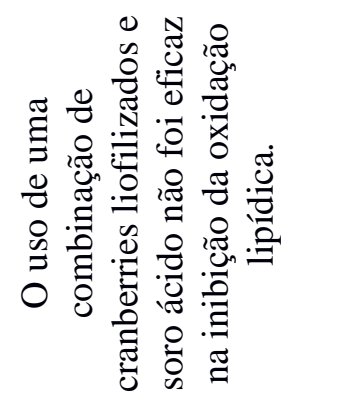 & 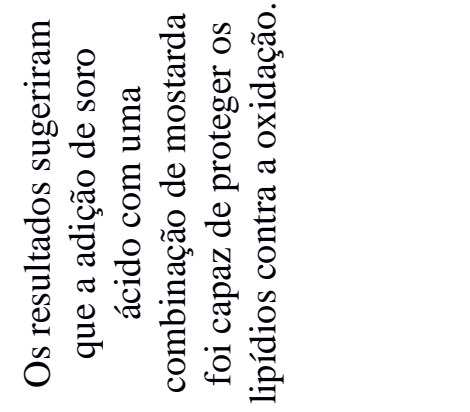 \\
\hline 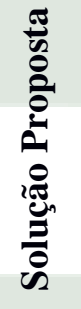 & 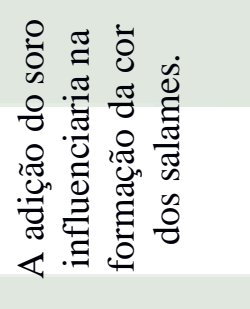 & 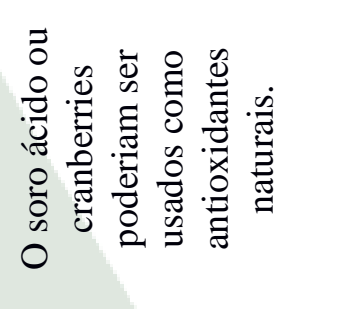 & 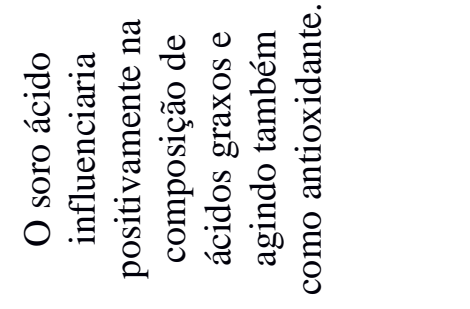 \\
\hline $\begin{array}{l}\frac{\pi}{60} \\
\frac{0}{0} \\
\frac{0}{0} \\
\frac{0}{0} \\
\sum \\
\sum\end{array}$ & 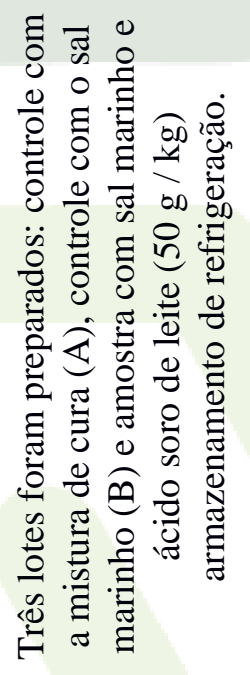 & 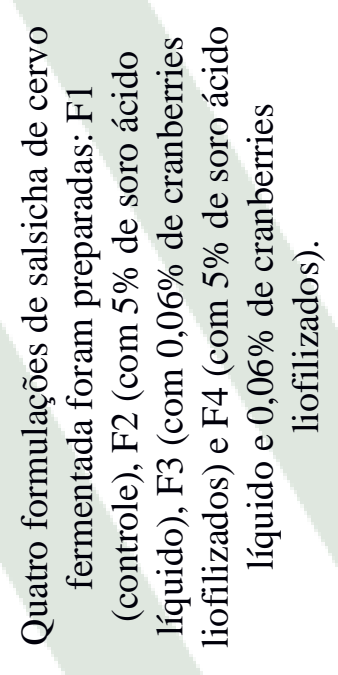 & 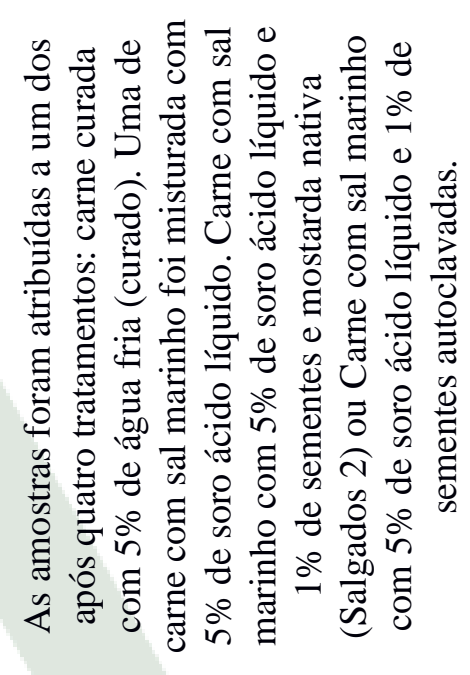 \\
\hline$\frac{n}{0} \cdot \frac{0}{0}$ & 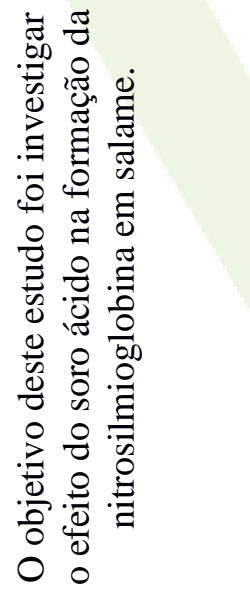 & 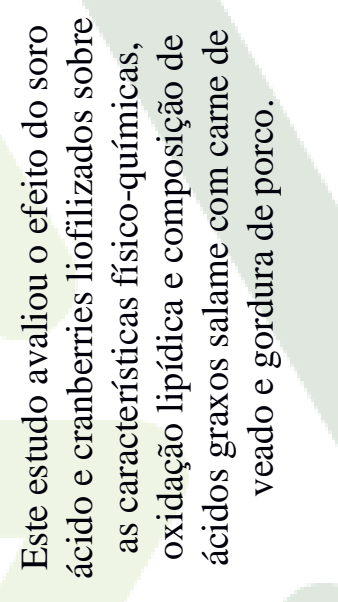 & 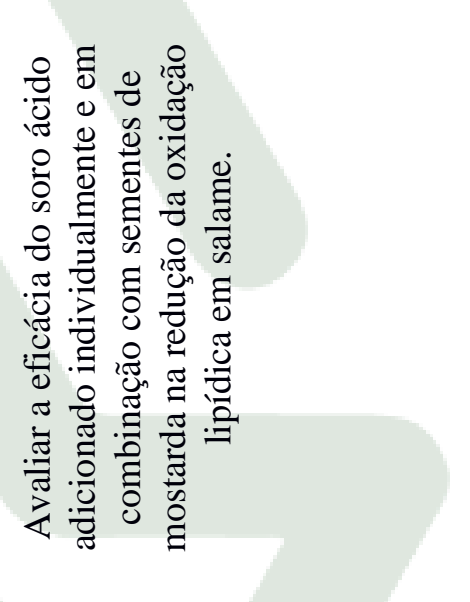 \\
\hline 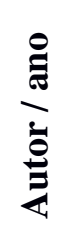 & 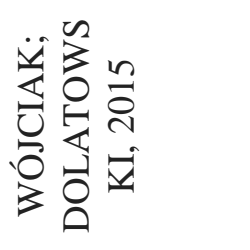 & 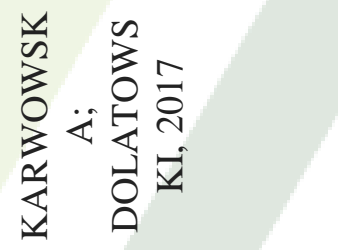 & 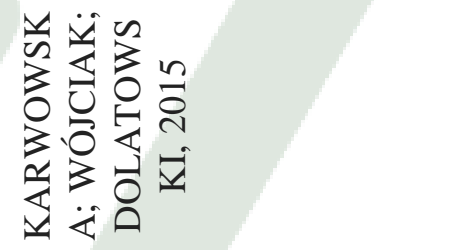 \\
\hline
\end{tabular}




\begin{tabular}{|c|c|c|c|}
\hline 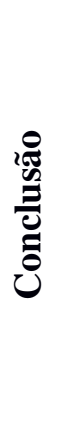 & 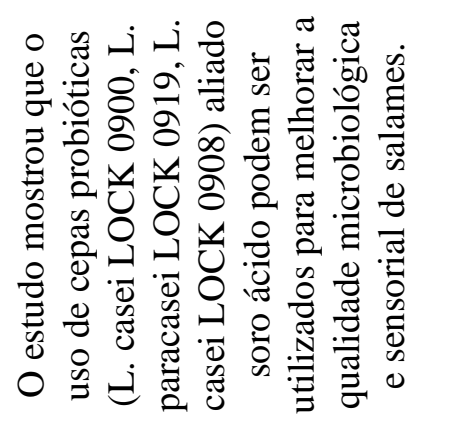 & 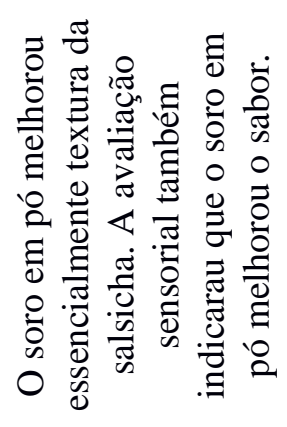 & 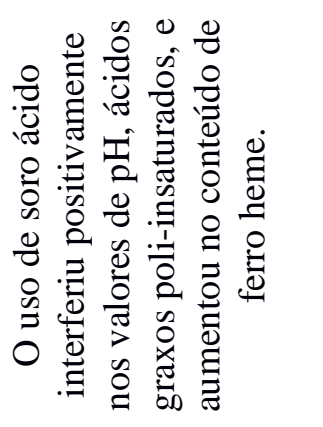 \\
\hline 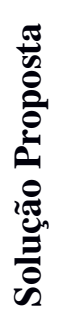 & 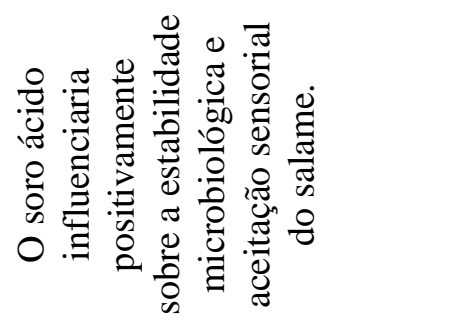 & 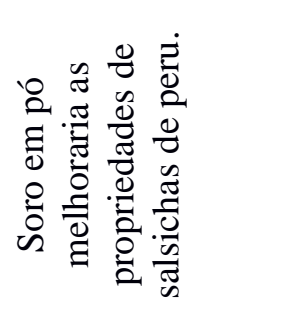 & 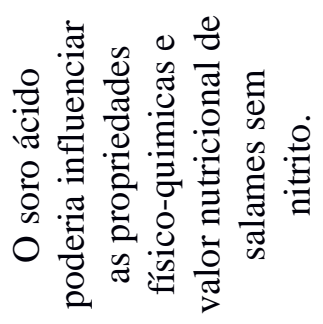 \\
\hline 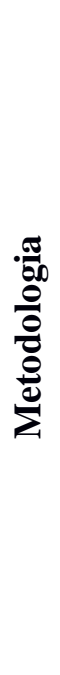 & 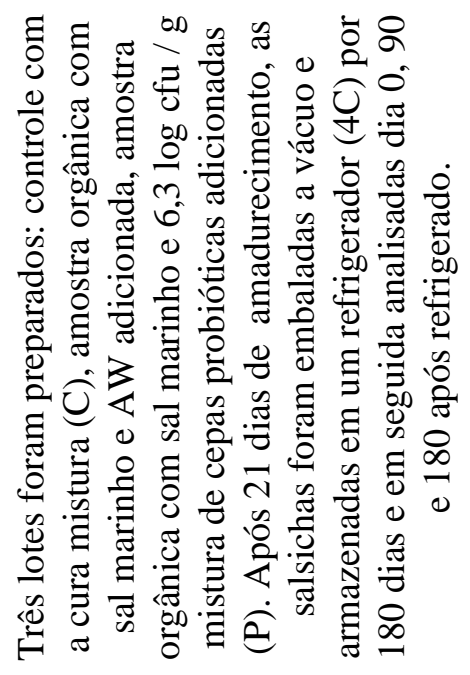 & 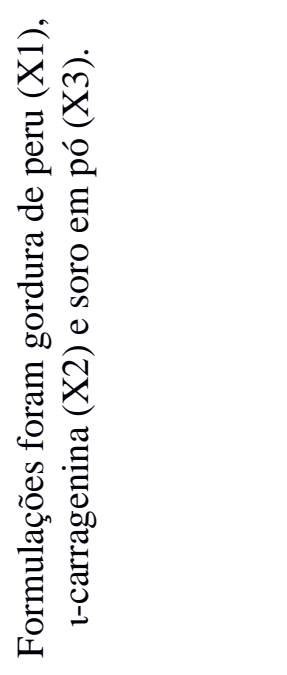 & 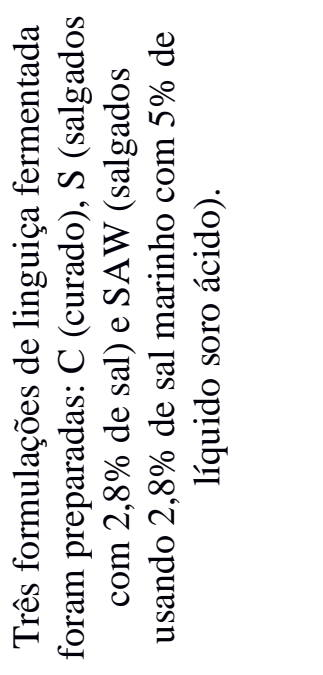 \\
\hline$\frac{\tilde{0}}{0}$ & 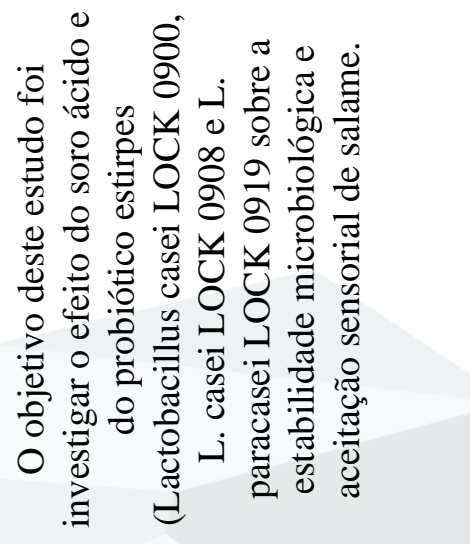 & 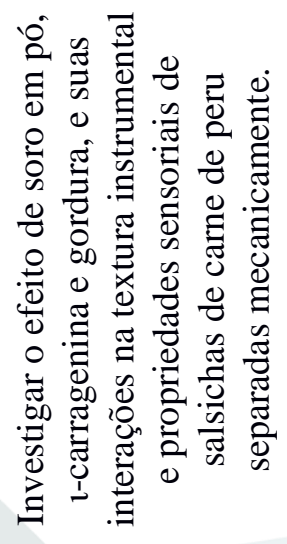 & 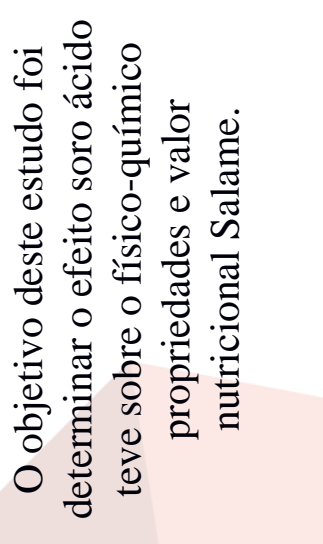 \\
\hline & 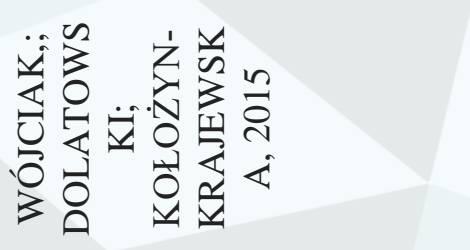 & 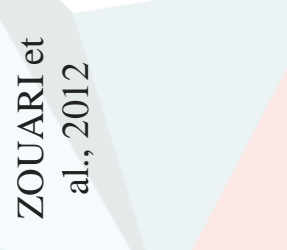 & 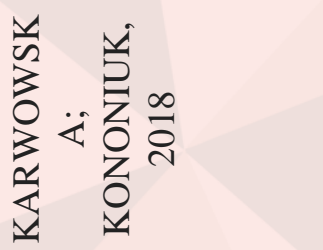 \\
\hline
\end{tabular}



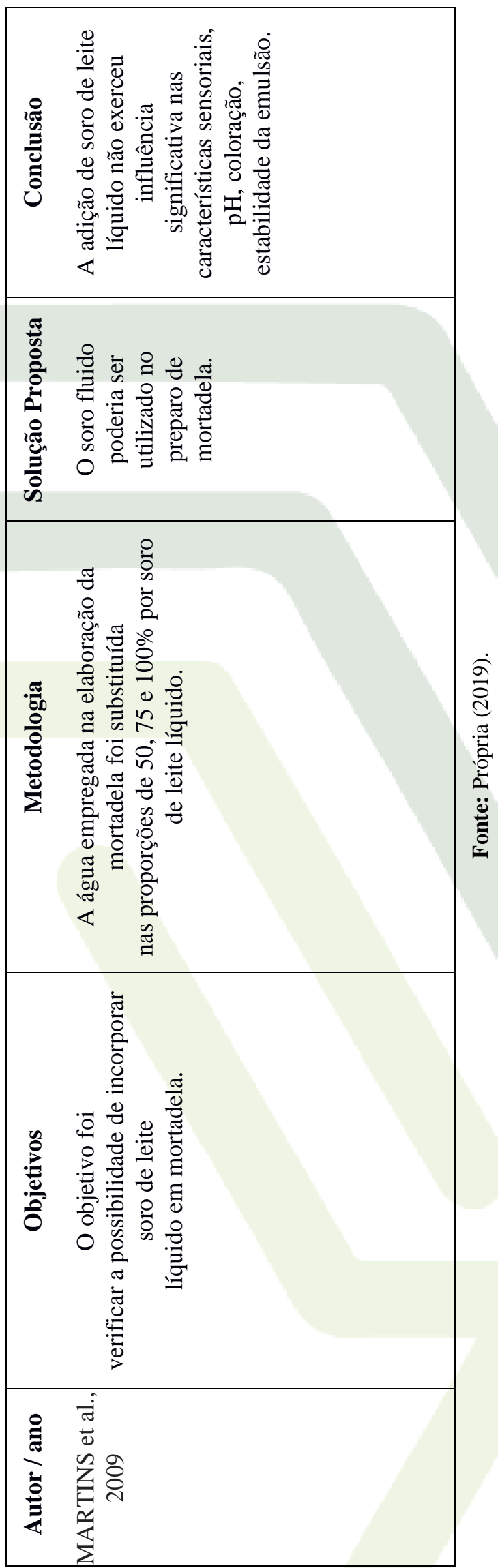


\section{Análise das questões}

Cada questão foi respondida em cada artigo, com o objetivo de se obterem resultados mais precisos mediante a análise das publicações, que serão discutidas em seguida.

Q1: Qual embutido foi utilizado no estudo?

A partir da análise dos artigos foi possível observar que o soro de leite pode ser utilizado em diversos embutidos. Vários foram os tipos encontrado em cada artigo como, linguiça no artigo 1, salame nos artigos 2, 3, 5, 6, 7, 8 e 10, salsicha artigo 4 e 9 e mortadela artigo 11 . Apesar da diversidade de produtos cárneos, o mais explorado nos estudos é o salame. Esse fato pode ser devido a produção que é um pouco mais complexa, pois passa por fase de fermentação e período de maturação vão contribuir diretamente para as características sensoriais do produto como sabor, aroma, e cor. Outra possibilidade é devido a composição do produto que contém alguns aditivos químicos como conservantes, antioxidantes, estatizantes entre outros, que muitas vezes podem ser prejudiciais à saúde, então a utilização de um substituto natural como soro de leite é uma saída eficaz.

Q2: Como o soro foi aplicado?

Pode-se perceber através das análises que várias são as formas de utilização do soro de leite nos embutidos, desde concentrados proteicos do soro como foi realizado na elaboração da linguiça no artigo 1 , soro ácido como foi aplicado nos artigos 2,3,4,5,6,7, 8 e 10 no preparo dos salames e de uma salsicha. Também foi utilizado na forma em pó, para aplicação em uma salsicha como mostrou o artigo 9, e por último inserção do soro de leite em sua forma fluida, que pode ser observado no artigo 11 produção de uma mortadela.

Assim, mesmo com as variadas formas de aplicacação do soro do leite, os artigos mostraram uma maior tendência a utilização do mesmo na forma de soro ácido. Isso ocorreu devido ao tipo de produto que estava sendo analisado, que boa parte eram salames, então a utilização do soro ácido tinha aplicação específica, ser introduzido substituído aditivos químicos, modificando também as propriedades físico-químicas do produto.

Q3: Os resultados da aplicação do soro foram positivos?

A aplicação do soro de leite nos embutidos apresentou bons resultados em relação ao que era proposto para cada trabalho. No artigo 1 a proposta era utilizar o concentrado proteico como substituto de gordura a produção da linguiça, o que através dos resultados pode ser constatado que foi eficaz a utilização, havendo redução de gordura na composição do alimento. Em outros artigos foi utilizado o soro ácido como antioxidante e conservante natural, o que em boa parte dos artigos foram efetivas, como no $2,4,7,10$, atendendo a proposta que era designada pelo objetivo do artigo, porém no artigo 6 e 3 os resultados em relação a utilização 


\section{EFEITO DA ADIÇÃO DO SORO DE LEITE}

como um antioxidante natural não foram boas, talvez influenciado pelo tipo carne, ou processamento que foi realizado, mas no artigo 3 mesmos não exercendo uma eficaz ação antioxidante, o soro ácido contribuiu para a melhora na cor, o que também pode ser observado no artigo 5, podendo ser utilizado para melhorar essa propriedade.

No artigo 9, pode ser visto que a utilização do soro de leite em pó trouxe benefícios para as propriedades sensoriais como, melhorando textura e firmeza do produto. $\mathrm{O}$ artigo 11 também mostrou positivas características nas suas propriedades sensoriais na elaboração da mortadela. Q4: Quais contribuições nutritivas o soro trouxe para essa pesquisa?

A procura por produtos que contenham menos aditivos químicos tem aumentado significativamente nos últimos anos. Visando isso a utilização do soro ácido se mostrou eficiente em vários artigos aqui analisados, mostrando resultados que influenciarão positivamente na vida e alimentação das pessoas. Os embutidos são alimentos muito gordurosos, então pensando nisso a utilização de concentrados protéicos como mostra no artigo 1, pode ser uma saída eficaz para continuar consumindo esse tipo produto, contribuindo assim nutricionalmente.

Q5: Quais interferências houveram para as propriedades sensoriais?

Analisando os artigos foi possível ver que todos os produtos apresentarão boa aceitabilidade, não mostrando diferenças ao ser comparado a amostras controle em relação as propriedades sensoriais. No estudo do artigo 9, houve até uma melhor aceitação das amostras que apresentaram o soro de leite em pó com maior aprovação no sabor e firmeza. No artigo 3, a cor foi bem característica, podendo assim ser notado nas análises tendo boa aceitação. Assim sendo, o soro de leite pode ser utilizado, pois não implicará negativamente nas características dos produtos.

\section{Discussão}

Como pode ser visto a partir da análise dos artigos e das questões, existem diversas maneiras de aplicação do soro leite sobre os mais diversos tipos de embutidos. Uma das formas de utilização do soro nos artigos aqui explorados são em concentrados proteicos, podendo ser aproveitados como substituto de gordura. A vantagem do seu uso é sua aplicação positiva no sentido de reduzir o teor de gordura nos alimentos. Se o objetivo do emprego do concentrado proteico fosse a elevação do nível proteico, teria que utilizar um maior percentual, o que talvez não fosse tão vantajoso, levando em consideração o preço desses concentrados.

Outra forma utilização do soro nos artigos é ele em pó, podendo ser observado que houve uma melhora nas características sensoriais, principalmente firmeza e sabor. Entende-se que o soro influencia positivamente de certa forma na estrutura do embutido. Outra forma de 
aplicação do soro que pode ser vista no artigo 11, é a utilização dele em sua forma fluida. Nesse estudo ele foi utilizado substituindo a água da composição da mortadela, o que foi positivo, já que quando comparado a amostra controle, não mostrou diferença significativa nos resultados das análises sensoriais. Além disso, é uma forma de aproveitamento do soro, que em sua forma fluida não é aproveitado pelas queijarias sendo desperdiçado no meio ambiente, trazendo assim prejuízos.

O soro ácido também é utilizado nos artigos aqui em estudo, sendo a principal forma explorado nesses trabalhos, 9 ao todo. Isso em decorrência do tipo de embutido que estava sendo utilizado, que era o salame, onde foi analisado como esse soro se comportaria agindo como um substituto de aditivos químicos que são utilizados na composição do produto. O soro ácido pode ser utilizado substituindo nitrito e nitrato, conservar assim o alimento e também contribuir para a cor característica do salame. O soro ácido também apresentou bons resultados agindo como um antioxidante natural, inibindo assim a oxidação nos produtos.

Em todos os processos de embutidos deve-se também levar em conta a qualidade da carne que está sendo empregada para elaboração do produto, e também o tipo de processamento que está sendo aplicado, fatores que vão influenciar de forma direta nos resultados obtidos.

\section{CONCLUSÕES}

A partir das análises realizadas nesse trabalho, foi possível perceber a influência exercida do soro de leite sobre os embutidos, agindo diretamente sobre as suas propriedades físico-químicas e sensoriais. Os trabalhos mostraram as várias formas que o soro de leite pode ser explorados na produção de embutidos, e como cada tipo de forma de utilização agia sobre os embutidos. Na forma de concentrado proteico, o soro foi utilizado eficientemente como um substituto de gordura, na forma de soro ácido, foi aplicado como conservante, antioxidante e também ajudou na melhora da cor de salames, apresentando bons resultados em relação a essas características. Na sua forma em pó, o soro ajudou a melhorar a propriedades sensoriais de salsichas como firmeza e sabor. Na sua forma fluida pode ser utilizado substituindo a água da composição de mortadelas, onde os resultados mostraram não diferir sensorialmente de amostras controle.

Todas essas características influem de maneira benéfica para o embutido a qual for aplicado, contribuindo nutricionalmente, pois poderá obter um produto que conterá menos teor de gordura, com melhores propriedades sensoriais, além de ingerir alimentos com menos aditivos químicos, o que é positivo para a saúde. Dessa forma a esta revisão sistemática é válida, pois permitiu por meio das análises desses trabalhos aqui expostos, identificar, avaliar e 


\section{EFEITO DA ADIÇÃO DO SORO DE LEITE}

interpretar de maneira imparcial as pesquisas, sobre o tema que foi proposto.

\section{REFERÊNCIAS}

ALVES, M. P et al. Soro de leite: tecnologias para o processamento de coprodutos. Revista do Instituto de Laticínios Cândido Tostes, v. 69, n. 3, p. 212-226, 2014.

BRASIL, Ministério Da Agricultura e do Abastecimento Secretaria de Defesa Agropecuária. Decreto no 9.013. Publicado em 29 de março de 2017.

CRUZ, A. T. F. Mortadela de frango com adição de soro de leite fluido. Dissertação (Mestrado) - Instituto Federal de Educação, Ciência e Tecnologia do Ceará, 2014.

FERREIRA, A. C. B; FONSECA, L; M; SANTOS,W. L. M. Composição centesimal e aceitação de lingüiça elaborada com reduzido teor de gordura e adicionada de concentrados protéicos de soro de leite. Ciência Rural, v. 39, n. 1, 2009.

GALVÃO, C. M; SAWADA, N. O; TREVIZAN, M. A. Revisão sistemática: recurso que proporciona a incorporação das evidências na prática da enfermagem. Revista Latinoamericana de enfermagem, v. 12, n. 3, p. 549-556, 2004.

MARTINS, N. N. T. L. L et al. Emprego de soro de leite líquido na elaboração de mortadela. Ciência Rural, v. 39, n. 3, 2009.

OLIVEIRA, D. F et al. Alternativas para um produto cárneo mais saudável: uma revisão. Brazilian Journal of Food Technology, Campinas, v. 16, n. 3, p. 163-174, 2013.

ORDONEZ, J. A. et al. Tecnologia de alimentos: Alimentos de origem animal. II. Porto Alegre: Artmed, 2005.

PACHECO, M. M et al. Efecto de la relación leche-lactosuero sobre las propiedades fisicoquímicas y reológicas en una bebida láctea fermentada. Ingeniería y Competitividad, v. 19, n. 2, 2017.

SAMPAIO, R. F; MANCINI. M. C. Estudos de revisão sistemática: um guia para síntese criteriosa da evidência científica. Rev Bras Fisioter, 2007.

ŠOJÍ, B et al. The effect of essential oil and extract from sage (Salvia officinalis L.) herbal dust (food industry by-product) on the oxidative and microbiological stability of fresh pork sausages. LWT, v. 89, p. 749-755, 2018.

TERRA, N. N et al. Emprego de soro de leite líquido na elaboração de mortadela. Ciência Rural, v. 39, n. 3, p. 885-890, 2009.

WÓJCIAK, K. M.; KARWOWSKA, M; DOLATOWSKI, Z. J. Use of acid whey and mustard seed to replace nitrites during cooked sausage production. Meat science, v. 96, n. 2, p. 750$756,2014$.

WÓJCIAK, K. M.; DOLATOWSKI, Z. J. Effect of acid whey on nitrosylmyoglobin concentration in uncured fermented sausage. LWT-Food Science and Technology, v. 64, n. 2, 
p. 713-719, 2015.

WÓJCIAK, K. M.; DOLATOWSKI, Z. J.; KOŁOŻYN-KRAJEWSKA, D. Use of acid whey and probiotic strains to improve microbiological quality and sensory acceptance of organic fermented sausage. Journal of food processing and preservation, v. 39, n. 5, p. 539-547, 2015.

WÓJCIAK, K. M; KARWOWSKA, M; DOLATOWSKI, Z. J. Fatty acid profile, color and lipid oxidation of organic fermented sausage during chilling storage as influenced by acid whey and probiotic strains addition. Scientia Agricola, v. 72, n. 2, p. 124-131, 2015.

WÓJCIAK, K. M; DOLATOWSKI, Z. J. Evaluation of natural preservatives in combination with acid whey for use in fermented sausage. Scientia Agricola, v. 73, n. 2, p. 125-133, 2016.

KARWOWSKA, M; WÓJCIAK, K. M.; DOLATOWSKI, Z. J. The influence of acid whey and mustard seed on lipid oxidation of organic fermented sausage without nitrite. Journal of the Science of Food and Agriculture, v. 95, n. 3, p. 628-634, 2015.

KARWOWSKA, M; DOLATOWSKI, Z. J. Effect of acid whey and freeze-dried cranberries on lipid oxidation and fatty acid composition of nitrite-/nitrate-free fermented sausage made from deer meat. Asian-Australasian journal of animal sciences, v. 30, n. 1, p. 85, 2017.

KARWOWSKA, M; KONONIUK, A. Addition of acid whey improves organic dry-fermented sausage without nitrite production and its nutritional value. International journal of food science \& technology, v. 53, n. 1, p. 246-253, 2018.

ZOUARI, $\mathrm{N}$ et al. Whey powder, $\mathrm{l}$-carrageenan, and fat interactions and their influence on instrumental texture and sensory properties of turkey meat sausage using a mixture design approach. International journal of food properties, v. 15, n. 6, p. 1233-1246, 2012. 